\title{
CRIANÇAS REFUGIADAS NAS ESCOLAS MUNICIPAIS DE CURITIBA
}

\author{
Jarina Muniz Nascimento' \\ Marli Pereira de Barros Dias ${ }^{2}$
}

\section{RESUMO}

presente trabalho tem como tema as crianças refugiadas nas escolas municipais de Curitiba e seu objetivo geral é compreender os desafios existentes no processo de recepção e de inclusão de crianças refugiadas nessas escolas. Estipulou-se como objetivos específicos: investigar o tipo de acolhimento e integração na instituição municipal, identificar os aspectos socioeconômicos que caracterizam essas crianças e investigar as dificuldades de comunicação entre professores, famílias refugiadas e a escola. Esta pesquisa bibliográfica/ qualitativa visa a destacar o papel e a atuação das práticas pedagógicas nesses cenários, a fim de incluir esses indivíduos, respeitando as suas identidades e culturas, de modo que se sintam acolhidos e que possam se integrar à sociedade brasileira de maneira efetiva, mas sem perder a sua própria identidade e cultura.

Palavras-chave: Crianças Refugiadas. Inclusão. Escolas Municipais de Curitiba.

Direitos Humanos.

\section{ABSTRACT}

The present work has the theme of refugee children in municipal schools in Curitiba, and its general objective is to understand the challenges that exist in the process of receiving and including refugee children in municipal schools

${ }^{7}$ Acadêmica da Faculdade UNINA. Licenciada em Pedagogia. E-mail: janiramuniz@hotmail.com ${ }^{2}$ Professora da Faculdade UNINA. Licenciatura em Filosofia pela Universidade Federal do Paraná (UFPR), Mestre em Sociologia e doutora em Teoria Jurídico-Política e Relações Internacionais pela Universidade de Évora, Portugal. E-mail: Marli@unina.edu.br 
in Curitiba. The specific objectives are: to investigate the type of reception and integration in the municipal institution, to identify the socioeconomic aspects that these children are inserted in and to investigate the communication difficulties between teachers, refugee families and school. This bibliographic / qualitative research aims to highlight the role and performance of pedagogical practices in these scenarios, to include these individuals, respecting their identities and cultures so that they feel welcomed and that they can effectively integrate into Brazilian society, but without losing its own identity and culture.

Keywords: Refugee Children. Inclusion. Curitiba Municipal Schools. Human rights.

\section{Introdução}

Este trabalho tem como tema as crianças refugiadas, mais especificamente, a recepção e a inclusão dessas crianças nas escolas municipais de Curitiba -PR. A finalidade é analisar o seu processo de recepção e de adaptação e os desafios encontrados pelos professores das escolas municipais de Curitiba, na realização desse processo, que é também de inclusão.

Devido às consequências das guerras, conflitos religiosos, políticos e catástrofes naturais, entre outros, as crianças refugiadas necessitam de um atendimento especial e de uma pedagogia adequada. Entretanto, a formação inicial dos profissionais da educação não oferece preparação suficiente para atender a essa demanda.

Nesse sentido, temos a seguinte pergunta de partida: Qual a importância das práticas pedagógicas inclusivas na inserção de crianças refugiadas nas escolas? Estabeleceu-se que objetivo geral deste estudo seria compreender os desafios existentes no processo de recepção e de inclusão de crianças refugiadas nas escolas municipais de Curitiba. Especificamente, pretende-se analisar o tipo de acolhimento e integração das crianças nas instituições municipais; identificar os aspetos socioeconômicos que envolvem essas crianças; e investigar as dificuldades de comunicação entre professores, famílias refugiadas e esco- 
la.

Por se tratar de uma pesquisa bibliográfica, os dados para o estudo foram selecionados e analisados com o propósito de identificar a implementação de programas nas escolas e sua efetividade no cenário da educação em Curitiba. Assim sendo, serão utilizados os dados referentes ao público em questão para a realização da análise pretendida.

É de suma importância que o profissional da educação saiba sobre a elevação no número e sobre o êxito dos programas em que essas crianças estão inseridas, bem como a respeito de seu desenvolvimento ao longo da sua existência. Portanto, esta pesquisa pretende destacar o papel e a concretização das práticas pedagógicas nesses cenários, para incluir esses indivíduos, respeitando as suas identidades e culturas, de modo que se sintam acolhidos e que possam se integrar na sociedade brasileira de maneira efetiva, mas sem perder a sua identidade.

\section{Os desafios da inclusão das crianças refugiadas nas escolas municipais de Curitiba}

Ao debater a Educação e os Direitos Humanos, é necessário a existência e o fortalecimento de uma sociedade democrática, que acolha as crianças refugiadas, conforme seus direitos garantidos por lei. Como o panorama democrático não faz parte da realidade de muitos países, segundo a Organização das Nações Unidas (ONU), as crianças refugiadas são as mais afetadas no mundo. Há um levantamento feito pela ONU apresentando dados sobre crianças com menos de 18 anos de idade, que revela sua difícil situação. Essas crianças são 52\% da população refugiada no mundo. Ainda, de acordo com a ONU, elas podem ter sofrido ou testemunhado atos de violência, fome e miséria ao longo da sua curta existência, e saíram de seus países de origem correndo riscos de abusos, negligência e explorações.

Há, no mundo, quatro milhões de crianças fora da escola, destacando-se que elas são mais da metade dos 7,4 milhões de refugiados que deveriam estar 
na escola. "Em 2017, cerca de 61\% das crianças refugiadas estavam matriculadas na escola primária, ou fundamental I, em comparação com uma média mundial, que é de 92\%" (ONU, 2017).

O número diz respeito também aos deslocados internos, crianças refugiadas e solicitantes de refúgio. $\bigcirc$ índice de refugiados inscritos para ter acesso à Educação chega a 23\%, bem abaixo da taxa global de 84\%. "Isso quer dizer que menos de um quarto dos refugiados no mundo alcança o nível da educação formal. Desta forma, 1\% consegue ter acesso ao ensino superior" (ONU, 2017).

No Brasil, a Constituição Federal (BRASIL, 1988), no art. 6, traz que "a educação abrange os processos que se desenvolvem na vida familiar, na convivência humana" (BRASIL, 1988). O Estatuto da Criança e do Adolescente (ECA) garante o atendimento à criança, independentemente de nacionalidade, religião ou cultura. Em seguida, a LDB apresenta, em seu art. $1^{\circ}$, que "a educação abrange os processos formativos que se desenvolvem na vida familiar e na convivência humana" (BRASIL, 1996).

Dessa forma, os Estados e as famílias são vistos como os responsáveis pela educação, efetivando direitos respaldados na Constituição, garantindo o acesso aos direitos que também se referem à educação igualitária, incluindo as famílias e as crianças refugiadas, pois a Constituição Federal assegura esse direito, independentemente de nacionalidade, cultura, religião, entre outras, e sem discriminação.

De acordo com a Convenção da ONU relativa ao Estatuto dos Refugiados, assim como a Convenção de Genebra, de 1951, em seu artigo 22, "os Estados Contratantes darão aos refugiados o mesmo tratamento que aos nacionais no que concerne ao ensino primário" (ONU, 1951, p. 11).

Portanto, os Estados de acolhimento têm que estar preparados para receber as crianças refugiadas, possibilitando a cada família e a seus entes uma vida digna e com oportunidades, incluindo a moradia, a educação e a saúde, que são direitos inalienáveis. A ACNUR, agência da ONU para os refugiados, criou uma cartilha para solicitantes de refúgio no Brasil, na qual informa sobre decisões, métodos, direitos, dando respaldo e auxílio à população refugiada no 
Brasil. Nessa cartilha, a educação é abordada de forma clara: "Os solicitantes de refúgio têm o direito de frequentar as escolas públicas de Ensino Fundamental e Médio, bem como de participar de programas públicos de capacitação técnica e profissional (ACNUR, 2015, p. 05).

No Estado do Paraná, há o Plano Estadual de Políticas Públicas para a Promoção e Defesa dos Direitos de Refugiados, Migrantes e Apátridas do Paraná (2014-2016). É uma proteção a mais aos refugiados, trazendo objetivos pautados de forma legal, mas, na aplicação, ainda é insuficiente. O comitê estadual, com o lançamento desse projeto, reforça as políticas públicas em defesa dos refugiados, mas não é possível verificar de fato a concretização daquilo que a teoria prega.

É essencial ressaltar que a causa geradora da saída do país de origem é uma crescente violação dos Direitos Humanos, e hoje percebe-se que, progressivamente, mais pessoas migram também para o Brasil, deixando seu país de origem em busca de paz, não sendo, portanto, uma migração por motivos econômicos.

Lidar com as questões sociais inclusivas, no atual contexto histórico, cultural e econômico do Brasil, ainda é um desafio. Porém, tal temática deixou de ser um possível problema em longo prazo e tornou-se algo presente. Um ciclo novo precisa ser iniciado, a partir da concepção de educação transformadora, em que todas as crianças têm direito à inclusão. Nesse contexto, o acolhimento é essencial nas escolas, e o professor pode ser um mediador nos momentos de dificuldades de adaptação da criança, para que haja tolerância, respeito e inclusão.

Atualmente, o portal da Prefeitura de Curitiba relata que, na rede municipal de ensino, há 485 crianças e estudantes estrangeiros, de 37 nacionalidades (CURITIBA, 2019). Segundo a Rede Municipal de Ensino, o acompanhamento dessas crianças está sendo feito, por exemplo, na prova Curitiba. O objetivo é que obtenham um desempenho positivo, que servirá para traçar as novas ações inclusivas e políticas públicas de qualidade efetiva de proteção e acolhimento (CURITIBA, 2019).

Essa prova Curitiba, aplicada em espanhol, foi utilizada como instrumento 
de avaliação, em março de 2019, para mais de setenta e dois mil estudantes da rede municipal, com o intuito de, sistematicamente, acompanhar o conhecimento de todos os envolvidos em língua portuguesa e matemática. A produção dos estudantes "foi avaliada considerando as especificidades do contexto e sob os princípios de inclusão e equidade presentes na rede" (CURITIBA, 2019). Entretanto, a vivência na prática é outra, pois o método de integração não atende toda a carência da criança nos seus diversos aspectos.

A Superintendente de Gestão Educacional da Secretaria Municipal de Educação, Elisângela Mantagute, explica que receber e acolher crianças e famílias refugiadas se tornou um trabalho transformador e fundamental para inserir essas crianças em uma educação que é garantia de todos (CURITIBA, 2019). De acordo com o portal da prefeitura de Curitiba, na Escola Municipal Doutor Pedrosa, situada no bairro Portão, em Curitiba, há uma aluna de 11 anos, refugiada da Venezuela, que está no $5^{\circ}$ ano e que deixou a sua mãe em janeiro de 2019 no seu país de origem, chegando ao Brasil somente com o avô e com o irmão mais velho.

A partir da história dessa aluna, a sua professora afirmou que ficou entusiasmada e agradecida pelo fato de a criança ter conseguido expressar os seus sentimentos, sonhos e alegrias. Esses pensamentos são revelados na seguinte afirmação feita pela aluna: "quero ser vaqueira porque amo cavalos". Mas ela comenta que as pessoas tiram "sarro" e acham distante o seu sonho. Porém, ela garante que vai fazer o que gosta, isto é, ser vaqueira, montar cavalos, cuidar dos animais, andar em campos verdes e tranquilos. Essa postura, cheia de esperança e fantasia, revela o seu potencial de superar os limites impostos a uma criança refugiada.

Conforme informações oficiais da Secretaria Municipal de Educação de Curitiba, essa aluna venezuelana foi acolhida pelos profissionais e alunos de forma calorosa. Informam que ela se sentia à vontade para expressar da sua maneira, a melhor forma de comunicação. Segundo a avaliação da pedagoga da escola, a sua adaptação tem sido rápida e ela está se destacando socialmente. Na fala da pedagoga, "a aluna está muito bem inserida e, mesmo com a semeIhança dos idiomas, existem adaptações que estamos fazendo para garantir a 
ela uma boa aprendizagem em língua portuguesa" (CURITIBA, 2019).

A Coordenação de Língua Estrangeira, além de atender as unidades, passou a proporcionar cursos de preparação para imigrantes e refugiados a fim de que haja a integração de todos os envolvidos. Aos professores, são quatro horas de formação, com um educador que conhece a política de atendimento e instrução de ensino para os alunos de outras nacionalidades.

Contudo, o acolhimento e a adaptação nesse curso são propostas curriculares legais de matrícula, com inúmeros procedimentos pedagógicos. Uma das principais recomendações é que o profissional de ensino compreenda que não existe uma sistematização no atendimento dos estudantes estrangeiros. Assim, antes de iniciar o processo, é preciso garantir o acolhimento para inseri-los em uma nova cultura escolar (CURITIBA, 2015). Marcos e Ângela Bussmann, também da equipe de língua estrangeira, são responsáveis pelo levantamento de quem são e em quais escolas municipais estão os estudantes vindos de outros países, além de organizarem e produzirem o material que orienta os profissionais das escolas no atendimento ao grupo imigrante. A dificuldade em localizar literatura e experiências de escolarização para estrangeiros no país fez com que a dupla de servidores desenvolvesse pesquisa e produção de material, a partir das experiências vivenciadas nas escolas municipais (CURITIBA, 2015).

As escolas, de certo modo, estão defasadas com relação à recepção de crianças refugiadas, todavia as metodologias utilizadas em sala de aula, de acordo com as informações divulgadas pela Secretaria de Educação do município de Curitiba, são bastante diversificadas e têm cuidado para que todos aprendam de forma eficaz. Nota-se também uma grande preocupação por parte dos professores, para que os estudantes entendam a seu tempo e que possam assimilar o conteúdo a sua maneira.

\section{Considerações finais}

Os direitos das crianças refugiadas e sua inclusão na educação ainda é uma questão complexa, que necessita ser mais pesquisada e difundida no Brasil. $\bigcirc$ 
que foi verificado é que há poucos estudos sobre o tema em foco, deixando lacunas para o conhecimento da história de vida e das necessidades dessas crianças.

Um dos maiores desafios das famílias refugiadas e crianças é a língua, pois as escolas estão despreparadas para atender esses sujeitos, visto que necessitam de intérpretes para que haja a comunicação entre eles. Na verdade, há modos de preparar os profissionais da pedagogia e os professores por meios de entidades que têm parcerias com a prefeitura, mas isso ainda é raro acontecer.

É necessária uma melhor formação docente para o trabalho com as crianças refugiadas, pois é um direito que elas têm. Entre os grupos mais afetados por guerras e perseguições, as maiores vítimas são as crianças e os adolescentes. Vivem de modo precário, são vulneráveis, marginalizados e, por conta disso, absorvidos no trabalho escravo, infantil e servindo aos grupos insurgentes, até mesmo como soldados. Sendo assim, é de extrema importância colocar em pauta a discussão de estratégias de inserção, inclusão e desenvolvimento das crianças refugiadas na educação de modo geral e nas escolas de Curitiba.

A reflexão é que as escolas recebam essas crianças de forma adequada, respeitando as suas origens e condições históricas, culturais e sociais, e sejam capazes de oferecer uma educação de qualidade, incluindo todos os sujeitos e que Ihes proporcione não somente aprender a ler, escrever e somar, mas que desenvolva todas as suas potencialidades.

Desse modo, é fundamental intensificar a luta pelo cumprimento dos direitos das crianças refugiadas enquanto sujeitos de direitos, especificamente a sua condição de infância, assegurando assim sua dignidade e sobrevivência. Além disso, a sua inserção no ambiente escolar é uma forma de melhoria do desenvolvimento individual e coletivo, a partir do legado cultural educativo produzido pela humanidade. 


\section{Referências}

BRASIL. Constituição da República Federal do Brasil. Brasília, DF, 1988. Acesso em: 01 dez.2019: acesso em 22 mai. 2020.

BRASIL. Estatuto da Criança e do Adolescente. Lei 8.069, de 13 de julho de 1990. Dispõe sobre a proteção integral à criança e do adolescente. Brasília, DF, 1990.

BRASIL. Lei de Diretrizes e Bases da Educação. Lei 9.394, de 20 de dezembro de 1996. Estabelece as Diretrizes e Bases da Educação Nacional. Brasília, DF, 1996.

BRUGGER, Lívia Cristina Eiterer. Método Montessoriano a Importância do Ambiente e do Lúdico na Educação Infantil. Revista Eletrônica da Faculdade Metodista Granbery. Disponivel em: http://re.granbery.edu.br - ISSN 19810377 acesso em: 16 mai. 2020.Minas Gerais, n.12, p.07, jan a jun. 2012.

Estudantes estrangeiros tem atendimento inclusivo na Rede Municipal. 17 de abr. de 2019. Disponível: https://www.curitiba.pr.gov.br/noticias/estudantes-estrangeiros-tem-atendimento-inclusivo-na-rede-municipal/50057 acesso em 16 mai. 2020.

Fundo das Nações Unidas para a Infância. Disponível em: https://www.unicef.pt/media/2766/unicef_convenc-a-o_dos_direitos_da_crianca.pdf\%20acesso\%2022/04/2020. Acesso em maio de 2020.

ONU. Assembleia Geral das Nações Unidas. Convenção das Nações Unidas sobre os Direitos da Criança. 1989. Disponível em. Acesso em maio de 2020.

Declaração Universal dos Direitos Humanos. 1948. Disponível em. Acesso em maio de 2020.

Declaração Universal dos Direitos da Criança. 1959. Disponível em. Acesso em maio de 2020.

SARMENTO, Manuel Jacinto. As culturas da infância nas encruzilhadas da 2a. Modernidade. 2002. Disponível em: Acesso em 16 mai. 2020. 